\title{
Integrating andragogical philosophy with Indigenous teaching and learning
}

Indigenous practices of teaching and learning provide a rich source of wisdom in the context of management learning. Whilst much work into the Indigenisation of educational offerings has produced place-based partnerships with First Nations people and custom engagement (see (Gainsford, 2018; Kwaymullina, 2019), little to no research has been produced bringing together Indigenous teaching and learning practices and andragogical philosophy. This is of particular significance as a much higher proportion of Indigenous learners engaged in higher education are mature age and more likely to enrol in external or intensive modes of education delivery (Behrendt et al., 2012: 8). Education framed by andragogy concepts have different expectations, including the central tenet of self-directed learning. Andragogy educational concepts enables adult learners to bring a mature, independent and integrated approach that engages their prior knowledge as a foundation for experiential knowledge and knowing (Dewey, 1996; Knowles, 1980).

The andragogical program we focus this study on is the MURRA Indigenous Business Master Class program as an example of a bespoke Indigenous centred business education program in the environment of a business school. Using a rich set of data collected from the alumni of the MURRA program, and through educator observation, we present four principles for Indigenous business andragogy. This article offers an Indigenous business andragogical framework featuring these four principles with an emphasis on the importance of the design of adult learning, that is not only focused on skills and knowledge development, but upon the culturally enriched learning environment. The four principles of the distinctive Indigenous business andragogy model focus on the intersection between teachers and learners - cultural knowledge and cultural ways of learning; collaborative learning; connected practice; and 
collective motivation. These four andragogical principles can be effectively implemented by management academics in collaboration with and by seeking engagement and leadership from Indigenous businesspeople and Indigenous academics.

How we prepare the learning space matters. It matters both in terms of the spatial reality of the learning space where it is located and how the place-based acknowledgement is held as important in the program and through the creation of spaciousness in the teaching program for group dynamics that bring in and reflect the 'emotional and political dynamics' (Vince, 2011: 333) that encompass learners' lives. For Indigenous learners, the spatial, emotional and political dynamics are further contextualised by collective inter-generational experience of the ongoing effects of colonialisation (Gainsford, 2018; Cajete, 2016). Indigenous learners have different, embodied experiences in their families of the impacts of colonisation, which in turn act as a cohesive agent 'drawing together' individuals in a sense of community (Peredo, 2005). Bringing these narratives and culturally embodied knowledges into the classroom acknowledges the breadth and depth of 'Indigenous cultural values and ethics that influence action' (Gladstone, 2014: 223). The fostering of cultural bonding and connections evident in Indigenous cohorts build collective motivation by linking cultural identity and pride (Bodkin-Andrews et al., 2017). Still, these descriptions of the learning space, we argue, are only acts of preparation for the education experience.

However there is little discussion of the predicament the business academy finds itself in when considering diversity and social inclusion (Minefee et al., 2017). Important steps have been made to include Indigenous learners and academics into business academy spaces, however the inclusion of pluralistic approaches to teaching and learning (Stewart and Pepper, 2011; Verbos et al., 2011) are relatively limited. This is acutely emphasised in the isolation faced by scholars 
trying to introduce Indigenous teaching and learning concepts into the business academy (Gainsford and Evans, 2017; Schwabenland, 2010). It seems that cultural learning approaches in business education may be considered by many as 'innovative', but driven by ethical and moral responsibility (Cummings and Bridgman, 2016; Hardy and Tolhurst, 2014; Lund Dean and Jolly, 2012) rather than as important inclusions into a contemporary business academy. Hence Indigenous business education remains as a separate consideration, socially and academically isolated.

Taking forward these dimensions, Indigenous business education environments are a confluence of 'how culture, teachers' and students' epistemological beliefs, instructional strategies, and learning environments interact more broadly' (Hardy and Tolhurst, 2014: 285). These elements provide for a holistic underpinning for andragogical environment. As academics in the higher education sector, we design program offerings that capture learners by appealing to their desire to extend their knowledge in order to achieve aspirations for their careers (Swain and Hammond, 2011). That being said, the inclusion of a culturally specific Indigenous business education offerings by business schools can create generative pathways and connection points for Indigenous business sector professionals, stakeholders and entrepreneurs. In this paper we assess how Indigenous teaching and learning philosophy, underpinned by andragogy, creates a stimulating learning environment for Indigenous business leaders. Focusing on the MURRA Indigenous Business Master Class program, taught at Melbourne Business School in Australia, we examine how Indigenous business owners develop acumen through collaborative and contextual learning practices inside the MURRA program, which builds business capability in the ecosystem of the Indigenous business sector. Further, we suggest that Indigenous innovations in teaching and learning can have an impactful influence on business leaders and the business 
academy more fulsomely; especially as calls for decolonisation and critical engagement of the often unquestioned, underpinning assumptions guiding business school curriculum and teaching programs become more and more urgent (Dar et al., 2020; Gaudry and Lorenz, 2018).

\section{Australian Indigenous Business Ecosystem}

The Australian Indigenous business sector is emergent. Post the 1967 referendum, when Australian Indigenous people were affirmed to demographically count, the predominate market opportunity for Indigenous Australians were as labour for non-Indigenous businesses (Schaper, 1999). Indigenous labour was controlled by settler-colonial land and business owners and relations with Australian Indigenous people asserted political and economic domination (White, 2011). Whilst this history and many histories of Indigenous peoples the world over demonstrates how capitalism is inherently racist, there is a rising movement of self-determination via business ownership and self-employment.

As of 2016, it has been estimated that there are now 17,900 Indigenous business owners operating in Australia, growing by around 30\% since 2011 (Shirodkar et al., 2018). Indigenous Australians are crafting and operating businesses in the neo-liberal capitalist systems. These Indigenous epistemic enabled commercial ventures counter the historically oppressed placement of Indigenous people in relation to the economy. Whilst it cannot be argued that this small but growing self-employed population addresses Indigenous inequity, Indigenous business ownership does create a different set of relations between Indigenous people and capital. Indeed, it is in the powerful mobilisation of Indigenous businesses that individual owners assert their own vision and make their own choices where to act and lead in the market, navigating the tensions between profit and purpose (Evans and Williamson, 2017a). 
In order to increase the number of businesses it is essential that all stakeholders invested in the Indigenous business sector commit to creating a holistic entrepreneurial ecosystem (Foley, 2006b; Altman, 2000). What is the Indigenous business ecosystem? Perhaps its best defined as an emerging structure, cultivated by a number of stakeholder groups such as individual entrepreneurs, government bodies and entities, Australian and international companies, the Indigenous social sector, Indigenous native title sector, banks and financing companies, philanthropic entities, the not for profit sector, Indigenous communities and families, Indigenous business advocates and organisations, Chambers of Commerce, politicians, a range of general public audiences and markets interested in and purveyors of Indigenous businesses goods and services. Exhaustive as the list may be, it demonstrates that there are many actors who have an interest in the success and growth of Indigenous business.

A strong Indigenous business sector will drive Indigenous financial independence, create wealth and future opportunities for Indigenous Australians (Langton, 2012; Shirodkar et al., 2018; Hudson, 2016). An important requirement of a self-determining holistic Indigenous business sector ecosystem is the development of business expertise of entrepreneurs across many areas of the economy. Business acumen is a key supply side feature of the Indigenous entrepreneurial ecosystem, as it, in turn, develops the growth of Indigenous businesses, and therefore supports broader Indigenous economic sustainability. Recent national research in Australia reports that the success of an Indigenous business is greatly increased by owneroperators having a post-secondary level qualification (Morrison et al., 2014). Furthermore, business educated managers and owners of Indigenous businesses play a substantial role in providing employment opportunities for the Indigenous community (Hunter et al., 2015). Consequently, we propose that growing Indigenous businesses skills and knowledge in Australia is at the very least a two-stage reciprocal proposition whereby the growth of strong and 
successful businesses is supported and showcased by a strong holistic Indigenous business ecosystem.

As the number of Indigenous businesses increase in Australia there is an opportunity to develop and deliver business education programs for the Indigenous business sector; indeed, there is an imperative (Hunter and Foley, 2014). This paper explores an Indigenous business education offering that draws upon Indigenous concepts through intentional course design and teaching methodology which embodies andragogical philosophy through partnerships with broad stakeholders of the Indigenous business sector. We provide an analysis of the connections between andragogical philosophy and Indigenous teaching methodology, constructing a theoretical framework through which we study the MURRA Indigenous business master class program. We contribute to scholarship in the field around management andragogy and to the conversation in this journal about the value of relational ontological collective knowledge creation in management learning.

Business educators can also greatly benefit from a teaching experience with established Indigenous entrepreneurs as they have a rich background and specific expertise within Indigenous culture, community and the Indigenous business sector. Most evaluation of Indigenous business program evaluations and research emphasise the positive experience of having non-Indigenous business academics engaged in the teaching of program (see Bajada and Trayler, 2014; Vitartas, Ambrose, Millar and Dang, 2015), however it is fair to surmise there has been limited research on non-Indigenous teacher experiences of teaching into Indigenous business programs. Indigenous learners prior knowledge and experience can benefit management learning environments, and importantly the learning experience as business owners make insightful links between theory leading to higher thinking about Indigenous business practices (Stewart and Pepper, 2011). Profit making economic initiatives often contest Indigenous 
collective structures (Verbos et al., 2011). These differences and challenges motivating

Indigenous business education in Australia to develop new and innovative frameworks to address the need.

\section{Andragogy Concepts and Indigenous Business Education}

Indigenous people are more open to ways of learning that respectfully engage their embodied knowledges and practical experience to shape their future knowledge (Evans and Sinclair, 2016). Andragogy requires the educator to facilitate an environment where skills and discipline specific knowledge can be delivered to adults learning together but also learning from one another (Knowles, 1980; O’Hara, 2003). Similarly Dewey (1940: 10) states that a relationship exists between the reflexive method of forming opinions, discussion and persuasion both in politics and classrooms, the places where the essentials of character are supposed to be formed. Dewey's notions supports the idea that active citizenship and participation in higher education can provide a space to challenge perceptions and paradigms thus motivating future thinking and behaviour patterns. A certain creative spaciousness to teaching and learning that draws upon students embodied experience, requires them to expand on this experience through introduction of new knowledge and theory, and encourages expansive discussion relevant to real life situations provides a starting point for business andragogy (Stewart and Pepper, 2011; Knowles, 1980; Dewey, 1996; Hjorth, 2003). Indigenous entrepreneurial education can be greatly enhanced by providing learning that directly relates to their Indigenous business experience within the andragogy framework so the newly acquired knowledge can be shaped through engaged and reflexive cohort dialogue. Harnessing this purposeful reframing of experience through knowledge building education can motivate individuals to critically reflect upon how 
they seek opportunities, as well as influence their future business direction within their cultural context.

Business education programs that recognise Indigenous entrepreneurs as independent learners with a collected pool of life and cultural experience as a rich learning source are at an advantage (Gainsford and Evans, 2017; Maritz and Foley, 2018). These cultural experiences often raise contention between Indigenous entrepreneurs, placing attention on a prominent tension of profit versus social purpose in business education programs (Gallagher and Selman, 2015; Gladstone, 2018; Garsombke and Garsombke, 2000). Indigenous entrepreneurs have a number of motivations to develop business skills and build Indigenous businesses and these areas are explored through the debate that arises from an Indigenous entrepreneur's connection to collective cultural values and building of wealth (Hunter and Foley, 2014; Hunter et al., 2015). Individual and collective motivations have been explored in relation to the Indigenous entrepreneurs participating in the MURRA program (Evans and Williamson, 2017b), where both profit driven self-actualising motivations track alongside prosocial collectivist aspirations. In the following section we outline the MURRA Indigenous Business Master Class Program as an exemplar Indigenous business education offering.

\section{Methodological framework}

This methodology underpinned by Indigenous Standpoint Theory (Foley, 2006b; Moreton-Robinson, 2013; Kwaymullina, 2016; Yunkaporta and Shillingsworth, 2020) highlighting the strengths and significance of Indigenous knowledges and ways of learning. "Indigenist research is research that gives voice to Indigenous people" Foley (2006b:30). As Indigenous researchers we assert that we are well positioned to conduct the research alongside 
Indigenous business owners. Indigenous Standpoint Theory has been utilised throughout the research as a framework that contextualises the historical and political positionality Indigenous business owners occupy, as Indigenous Australians are relatively new to the modern descriptors of self-employment post citizenship rights in 1967. Indigenous knowledges are unique in meaning and often challenge Western paradigms, and are recognised in this context as traditional ways of life that have been generated through local communities over a long period of time (Nakata, 2004). These knowledges are nuanced to each Indigenous community as differing cultural practices have been passed on from one generation to the next through oral traditions (Yunkaporta and Shillingsworth, 2020; Foley, 2003). Indigenous research is a foundation of cultural intelligence that links an Indigenous researcher with Indigenous research enabling Indigenous voices and worldviews to be promoted in academic spaces. Consequently the power of the interpretation comes from a central Indigenous understanding and viewpoint.

Indigenous Standpoint Theory has been utilised throughout the research primarily so that participants are able to contextualise their current situation according to political and historical struggles, drawing on information from the past pre-dating their own lifetime and linking this information to how past histories and political implications affect their current business situation (Moreton-Robinson, 2013). Indigenous research participants reflect on the strengths and challenges and recount circumstances that connect time and or place. Therefore, providing voice to have freedom and autonomy during the research process, creating a space for Indigenous viewpoints and worldviews to be amplified (Kwaymullina, 2016). Indigenous Standpoint Theory pivots around the central concern that Indigenous researchers are best placed to research Indigenous people (Foley, 2006). Both parties are able to recognise Indigenous ways of knowing, 
creating connection and benefit in holding Indigenous practices in high esteem to generate involvement and contribution from the Indigenous community.

In the research process Indigenous business owners operate their businesses, which can be understood as vehicles for self-determination, and therefore this research methodological framework emphasises the agency of Indigenous participants in this study but importantly and also situates the knowledge building participants and researchers do together through this research by linking this information to how past histories and political implications affect their current situation (Yunkaporta and Shillingsworth, 2020). Through the interview schedule, Indigenous research participants reflect on the strengths and challenges and recount circumstances that connect across time and or place.

The research interviews considered Indigenous cultural protocol and were structured to converse with MURRA alumni in a meaningful and culturally salient manner following essential cultural practices (Dunbar and Scrimgeour, 2006). The use of culturally appropriate language, syntax and interview technique were paramount to enable respondents to feel a sense of cultural safety in the interview discussion process (Foley, 2006b). This research interaction and discussion benefited from an Indigenous researcher which creates a level of ease and understanding during the research process. The diversity of rich responses from Indigenous participants emerged through a double layered analysis from thematic to narrative, which provided a framework when listening to interview responses. With each layering of analysis nuances of speech, contextualisation and cultural reflexivity were expressed through storied ways of knowing (Archibald, 2008). Storytelling [storied ways] brings an opportunity to engage with an Aboriginal worldview, to use narrative as an inquiry into ontology and one's connection to people and place (Somerville et al., 2010). This brings benefits to all Australians seeking stories of Country, connection and identity. 


\section{MURRA Indigenous Business Masterclass Program}

The MURRA Indigenous Business Master Class Program was established in 2012 by the Melbourne Business School in partnership with Kinaway the Victorian Aboriginal Chamber of Commerce. The MURRA program was developed in response to community calls for business education in Victoria. The program provides an Indigenous contextual cohort educational model to assist Indigenous entrepreneurs to increase their business skills. The six masterclasses (strategy, finance, human resources management, negotiations, marketing and leadership) are offered in three four day intensive residential blocks delivered by majority Melbourne Business School faculty. The cohorts participating in the MURRA program are representative of over 15 different industry sectors and from all across Australia. In 2020 the MURRA program has 175 graduates that have successfully completed the business program, with a $100 \%$ participant attainment. The program has been delivered nine times and each cohort is defined as a 'Generation'.

MURRA in the Woi-Wurrung language of the Wurundjeri people of Melbourne, Australia means fishnet. It is a metaphor provided by the Wurundjeri community to represent the Indigenous andragogical framework established to build business acumen capability of the MURRA Indigenous participants. A fishnet is a woven technology that acts as a funnel to capture. The net attracts and captures. The net constrains and contains, funnelling those captured into a defined space. Now let us augment the utility of a fishnet. Imagine it as a liminal space where those captured are there by choice. They have swum towards the fish net. Now inside, in this special body of water, weir, the resources and stock are bountiful. Those captured are nourished. Those captured are nourished in relationship to each other. Once this time of nourishment is complete, the mouth of the fishnet opens, allowing the captured to return. This 
metaphor demonstrates the technical utility usefulness of the fishnet, and the cultural/spiritual dimensions present in the space of the MURRA.

MURRA students identify as Indigenous entrepreneurs. This is either a self-initiated identity or entrepreneurial identity bestowed upon enrolment in the MURRA program. This discipline specific business program delivered in intensive residential sessions is structured so that participants gather business knowledge, establish vital business networks and receive significant business mentoring support. This education program is provided in a cohort education model that has a strong emphasis on collaborative teaching and learning methodologies practiced through andragogy teaching framework (Imel, 2002). For example, the MURRA program encourages students to take control and responsibility of their own learning (O'Hara, 2003; Knowles, 1980). Students consider purposeful business content that they relate specifically to their own needs. This information can assist students to decipher content that can connect to their current circumstances enabling them to apply strategies for individual business growth and connect with other Indigenous businesses for beneficial social outcomes.

\section{Research method and analysis}

Extending the success of the teaching program, an Australian Research Council Linkage project investigating Australian entrepreneurial leadership was conducted between 2014-2018 in partnership with Kinaway, Victoria's Aboriginal Chamber of Commerce and Supply Nation, Indigenous supplier diversity organisation. Ethics clearance authorised the researchers to conduct semi-structured interviews with successful cohorts of the MURRA program as well as surveys. The research implemented a multi-method longitudinal approach to investigate the impact of the 
MURRA program on the leadership behaviours and business routines of Indigenous entrepreneurs and the outcomes of their firms. Author Two, an Indigenous qualitative researcher, conducted the semi-structured long interviews with the MURRA alumni from cohorts one (2012) to four (2015). Fifty-five interviews and sixteen follow up interviews with Aboriginal and Torres Strait Islander entrepreneurs from across Australia were gathered to explore the phenomenon of Indigenous entrepreneurship and leadership (See Table one for an overview of the follow up interviewee demographics). Follow up interviews were offered to all fifty-five interviewees. The 16 represent those that accepted the invitation to re-interview two to three years post the initial interview (conducted during the year they participated in MURRA). Participants have been in business for varying amounts of time - providing a range of experiences of how Indigenous entrepreneurs shape their business and what motivates them to achieve their vision of success. The second-round interviews focused on MURRA alumni reflecting on the impact the program had on their firm and mindsets; on their contributions and leadership in the Indigenous business sector and their own Indigenous communities; and the cultural dimensions of their businesses.

\section{INSERT TABLE ONE ABOUT HERE}

This interview data was complemented by the autoethnographic diary notes made by Author One during the MURRA program in 2016. This second study was nested inside the larger ARC project specifically focused on understanding andragogy methods supporting the MURRA Indigenous Business Master class to develop Indigenous businesses in Australia. Ethics clearance was achieved for process consent with individuals participating in the MURRA program in 2016. 
Author One was approved to make notes as to the educational andragogy, not on individual participants in the learning environment. Author One is an Aboriginal teacher and academic. Using the lens of educator, Author One focused on assessing the andragogical techniques of the teaching staff and the Program Director during the delivery of the MURRA program. These diary notes were taken under ethics clearance and subject to process-consent each time the intensive learning block began. All of the participants in Generation Five of the MURRA program gave consent to the presence of the researcher.

We instigated an auto ethnographic method as we were specifically interested in how Author One made sense of the teaching and learning environment created in the MURRA program. As an Indigenous educator with a subject expertise in Indigenous teaching pedagogy and Indigenisation of curriculum, Author One was investigating their knowledge within a new context of business education. The process of making sense of the teaching and learning Author One was witnessing was processed in an analytic autoethnographic tradition (Anderson, 2006) whereby the embodied Indigenous knowledges, academic and personal experiential knowledges were brought into interaction with the classroom situation. The output of the research included 24 pages of notes, drawing of andragogical insights and relationships between different approaches by teaching staff and the Program Director. Author One engaged in not just note taking, but transposing idea, creative connections with traditional language form, through drawing and through personal integrative reflection reflecting the evocative autoethnographic tradition (Ellis and Bochner, 2016).

Inductive thematic analysis approach was used for the qualitative interview analysis. The data was transcribed, shared with the participant and verified before coding by theme. The analysis phase of the research was conducted over many months as it was integrated with the 
insights developed through the autoethnographic research. The MURRA program is run in three four day intensives with at least a month sometimes two months in between the Masterclasses. This allowed the researchers an opportunity to reread and deconstruct interviews several times independently. Author Two did not know the participants interviewed in the qualitative interviews as they had previously completed the MURRA program. This fresh perspective was also of great value, as the researchers workshopped together triangulating the autoethnographic insights, the participants voices from the interview transcripts and the fledgling theory building Author Two had begun during the larger ARC project.

Whilst the qualitative interviews did not focus on the teaching and learning of the MURRA program, the interview schedule did include questions asking participants to discuss how they make sense of their Indigenous identity, and their Indigenous community, in relation to their business/career. These questions invited participants to engage in reflection on the interconnections between business, Indigenous knowledges and practices, and their own sense of self. In order to understand how Indigenous entrepreneurs acquire business capabilities from Indigenous business programs, we were interested in how a business education program might provide a space for this kind of reflection and identity work (Sinclair, 2007b).

Both researchers spent time together energised by the richness between them, one seeing the MURRA program for the first time to provide a new perspective, and the other who had a long standing engagement with the program, bringing forward the voices of the participants. The analysis of the findings from both the qualitative research and insights from the autoethnography started to illuminate how the program created a space for learning and identity work (Carroll and Levy, 2010) where Indigenous knowledge and practices are central. Together, we focused on how participants responded to the education and acquired the learnings. The MURRA program 
focuses on the building of individual business skills through collaborative and self-directed andragogy processes. Second, we examined how or if students utilise their learnt business skills to inform their current business situation. Third, we investigated the peer-to-peer interaction and the exploration of social capital capabilities that arise from MURRA participants connections. The outcomes of the analysis provided the thinking leading to the four principle framework featured in the findings section.

\section{Findings: Four principles for Indigenous business andragogy}

This study contributes to the understanding of how andragogy methods can be used successfully in Indigenous business education because they recognise that adult learners are motivated and self-directed which contributes to sustainable learning practices to achieve set goals (Knowles, 1984). Andragogy also posits that an adult is someone who has an assumed societal role in which the learning can inform socially productive actions (Darkenwald and Merriam, 1982). Research findings illustrate that andragogy methods play an integral role in the process of teaching Indigenous business education. Further, research findings from both qualitative interviews and autoethnography illuminate that the role of the Indigenous cohort in bringing Indigenous knowledges, culture, business experience and expertise in a supportive and collaborative way of working as a group generates the connective and positive andragogical space. With that in mind we propose four principles towards an andragogy framework for Indigenous business education. 


\section{Principle 1: Cultural Knowledge and Cultural ways of Learning}

Indigenous learners hold and apply embodied and experiential cultural knowledges, and use cultural practices such as storytelling to contextualise and respond to curriculum content

The Indigenous cohort enters the learning space with a life full of experience, knowledges, cultural and business practices to share. Building upon Knowles (1984) focus that learners enter education with a stock of experience, Indigenous learners bring embodied experience and knowledge to the learning environment which frames their approach to contextualise business content and more specifically attuned thinking and experience of the interface between Indigenous culture, identity and capitalism. This politically charged entry is also about creating pathways for more Indigenous business people through access and sharing of knowledge.

Do you know what? I'm thinking more about how to get other Torres Strait and Aboriginal people into the same space I am. But not only that, it's realising that we are, it's a natural ability we've had, we've always had, but I've found now that all we need to do is know the rules and play our own game (Generation Four participant)

Coming into business school and/or business education brings with it a collective responsibility not just to forge a path, but to make sense of the rules of the game. MURRA participants conveyed how they made sense of the teaching and curriculum not just as it related to their firm, but as an Indigenous person. Learners work to contextualise curriculum responding through storytelling. Telling cultural stories, stories from their life, examples that are picked up 
on by other members of the cohort as they work to interpret the curriculum through past lived experience (Boje, 2008; Vygotsky, 1978).

It's about the rest of the world understanding how we live our culture, and that's what I realise now, is that the best way for any Indigenous business is to involve their culture completely in the business and just understanding the rules of engagement (Generation four participant)

Indigenous cultural protocols and how they relate to business is discussed and challenged among participants to work out cultural boundaries relating to business. Some participants assert their cultural knowledge and generously share with other participants their rich cultural background (Evans and Williamson, 2017c), while other participants are eager to learn about others Indigenous culture because they have not grown up inside Indigenous cultural traditions. Using cultural ways of learning enables some participants the opportunity to demonstrate in the classroom a profound sense of business expertise within the context of Indigenous business practices. Within the contextualisation process individuals increasingly benefit from the collective cohort's ability to relate business and cultural content to current Indigenous business situations. This process is facilitated naturally by the cohort model and is assisted by relationships built on cultural commonality and likeminded business experiences.

Teachers of the MURRA program are primarily non-Indigenous Business academics. They deliver discipline specific content to an all-Indigenous cohort. Whilst the academics have not been the focus of the study, we note that this would add another critical dimension to an 
Indigenous business andragogical framework (Gaudry and Lorenz, 2018). In this learning engagement the MURRA participants become the experts in relation to Indigenous business contexts, providing academics insights into business processes they rarely have access to. Individuals offering narratives about cultural expertise are supported by the cohort, leading to a group interaction between teacher, content and participants. These interactions often look like participants responding to teacher led content with their cultural and business knowledge, which is then critically built upon through peer-to-peer interaction of the cohort. This relational learning style is an Indigenous way of learning grounded in situational and cultural experience (Hardy and Tolhurst, 2014).

...the networks and the colleagues ... [have] helped me to ... talk about Indigenous thought leadership, our insight it's more than just intellectual property. It's our whole experiences and perspectives and world views that we need to be packaging it up as a saleable product... just show other businesses, this is an Indigenous business... (Generation Three participant)

The cohort work collectively to not just make sense of the tensions they experience between their cultural identity and doing business in the contemporary marketplace, but to frame the discourse through thought leadership. MURRA participants shared stories of how they experience and challenge the cultural boundaries they experience in regards to expectations from their communities to give back because of their economic success. These community level considerations challenge individual entrepreneurs about their transparency in giving back to Indigenous communities, but also about their legacy and more generally the way Indigenous communities' benefit from the operation of their business. The teaching and learning 
environment creates a space for individuals and the group to explore how culture and community interplay with their business. Whilst sensemaking through storytelling provides one strategy, and collectively working through the cultural tensions that emerge is another; participants also assert cultural value in figuring out how they harness their growing social and economic capital for the purpose of benefiting the wider Indigenous community.

It's about the rest of the world understanding how we live our culture, and that's what I realise now, is that the best way for any Indigenous business is to involve their culture completely in the business and just understanding the rules of engagement.(Generation Four participant)

Recognising Indigenous cultural complexities within the Indigenous business space creates contention in the cohort, providing the facilitator opportunities to encourage the group to question standard business curriculum, and uphold Indigenous way of doing business. The standard business curriculum sets out the 'rules of engagement' but it is in what the group finds together as they dialogue about achieving the right balance between dual objectives, a business mission and cultural integrity. Indigenous entrepreneurs analyse and find solutions to these critical contentions collectively, bringing to the fore cultural analogy and ways of thinking.

\section{Principle 2: Collaborative Learning}

Indigenous learners value the opportunity to collaborate and share their cultural and business knowledges with peers and educators. 
During the MURRA program Indigenous entrepreneurs have the opportunity to build relationships with fellow members of the cohort through program interaction and collaborative learning activities. Participants proactively connect on a cultural, personal and business level from day one. The intensive delivery of the program, facilitated by having participants stay, eat and learn in the same building, aims to build strength in the personal ties of the group. Often participants report they don't have a lot of time outside of work and family commitments to network, so the cohort provides a connection on many levels. From the first session, participants are encouraged to contribute to class content about their business practices and benefit from insights into fellow Indigenous entrepreneurs' challenges. Participants are also intentionally moved each day to encourage broad interactions across the cohort, contributing to a feeling of collaborative learning alongside lots of pair, trio and group work. This intentional interaction strategy, engagement and prior business knowledge becomes an important component underpinning the program andragogy. With cultural knowledge, connections and networks laying the foundation of trust, respect and inspiration for meaningful and collaborative learning begins to take place.

But there's something psychological too, I think, that we shouldn't overlook, when you get this sense that you're part of something bigger than yourself. I'm in business, but it's just heartening for me to know that there's other people like me out there that have the same sort of striving and that if they've got issues, or I've got issues, we can connect. It's a bond, the bond we've got, no one will ever take away... We bonded together and we all went through that experience together, and no one can take that away from us. (Generation Four participant) 
Whilst the learning in the classroom and how the individual participants apply that to their businesses is a key aim of the program, another is generating a sense of becoming a generation of Indigenous business leaders who have the responsibility for contributing to Indigenous economic self determination. Participants in the MURRA program reported this mindset shift, of being 'part of something bigger than yourself', as something that came about from deeply engaging in the collaborative learning environment. As Indigenous business people, participants spoke about feeling "very lonely...forg[ing] that new pathway" (Generation Two participant) into business as often not just the first generation from their own family in business, but often as the only Indigenous person that they know doing business. "That's what I love about MURRA is that meeting with other Indigenous entrepreneurs who are trying to achieve success in running a business in their own ways" (Generation Two participant).

Exploring business and cultural knowledges through problem-centred activities (Kolb and Kolb, 2009) challenged the conventional business concepts through engaged dialogue about cultural expectations. Strong relationships are foundational as participants find ways to do business together, to help each other out, and most significantly create collective Indigenous business sector initiatives like Indigenous Business Month.

I think that having alumni to connect with and talk to other people who have gone through that program, and I think initially like Indigenous business month was a really great initiative that came out of last year's cohort (Generation two participant) The collaborative learning environment generated a drive in the collective to create ways to connect ongoing outside the educational program. Indigenous Business Month was an ideal vehicle initiated by Generation Four to showcase Indigenous business across Australia and 
communicate this new discourse or way of thinking and talking about Indigenous business in Australia. Building a sense of belonging through relational bonds is imperative to this andragogic process. The fabric of belonging woven through the learning collaboration generated a sense of a shared identity, as Indigenous people and now as Indigenous business leaders. This maturing of the group granted them collectively space to reconcile tensions that arose from differences of opinions, cultural knowledge and ideology. These experiences impacted the collaborative learning process in both positive and negative ways, sometimes exposing differences and sometimes exacerbating difference. Yet the strength of what brings the cohort together to overcome these tensions is testament to the value the group holds in the collaborative learning process of the MURRA program.

Bring back to our family and community in that spirit of paying it forward and keeping true to our roots and so forth. All the MURRAS I've talked to, it's all about you know, retaining culture and our heritage and our background and all of that. That's an equally important part of the agenda as is being a profitable business (Generation Four participant)

Participants talk about the MURRA agenda being about promoting profitable businesses and promoting Indigenous leadership, but more than that, the program provides participants a collective to operate within. The collaborative learning environment provided a culturally safe space to explore challenging business concepts and knowledge, so that even when an individual was feeling overwhelmed other cohort members were able to sit alongside them, or take them for a coffee to help reengage the person back into the learning. For some participants this positive learning experience developed a confidence that became the foundation to explore further 
business education opportunities within the tertiary business education environment. For instance, fifteen alumni have gone onto further postgraduate management degrees and five alumni have undertaken doctoral studies.

\section{Principle 3: Connected Practice}

Indigenous learners value learning activities that connect theoretical concepts and the practical elements of their learning to Indigenous community need.

Indigenous entrepreneurs identified that business methodology and concepts learnt through the MURRA program were often new concepts and were easily applied to their business. Participants practiced business learnings with fellow participants in class relating them to their own business context. This process of trial and error refined Indigenous entrepreneurs' skills relating to business practise. Authentic business situations assisted participants to gain skills that could be immediately applied to current business situations (Knowles, 1984; Dewey, 1933). Moreover, focusing on an individual business challenge drew the cohort together as they problem solved a complex business situation.

I was able to bring to the table for my business a marketing strategy...that marketing strategy identified some key areas in the company, particularly around branding my company... have been introduced. And as far as results, I'd say comfortably that that marketing strategy has worked. (Generation One participant)

A significant majority of participants readily applied learned knowledge to current business situations when returning from the MURRA program. In the post program interviews 
they reported strategic changes to business operations implemented due to the learning in the MURRA program. Participants identified the specific skill or strategy that they implemented and how this adaptation had made a difference in their Indigenous business. The MURRA education content is adapted from a mainstream business curriculum by MBS, contextualised by the experience of Indigenous entrepreneurs to make the content more relevant to Indigenous business practices. Connecting business curriculum to practice enables students to relate educational content to their own social and cultural circumstances making the learning more relatable and applicable.

MURRA participants clearly articulate their cultural knowledge and reflect on their historical circumstance while linking cultural expectations to business contexts. Indigenous cultural protocols and business structures are discussed and challenged which enables participants to work and learn together to build strong entrepreneurial networks. In this way, participants demonstrate their prior knowledge and strengths relating to both cultural and business contexts.

I like that with MURRA in that it brings people from different streams. But actually, the collective knowledge within the room and the opportunity for that cross-genre collaboration, I think, is huge. You know, a lot of these social networks, social enterprises now, bring people from different spheres together to solve problems (Generation Three participant).

The richness participants bring into the room was as exciting or more so than the business content taught in the formal sessions. Creating space for participants to connect with each other about their businesses, about their challenges, is central to the program and program design. Usually from the first day of the program we see participants begin to establish business 
possibilities or create new opportunities by connecting their practices or solving larger problems together. This process is facilitated naturally by the cohort model and is assisted by relationships built on cultural commonality and likeminded business experiences. This Generation Three participant found a strong connection with a fellow participant that was influential in their development:

[they] said to me, you've got to draw your mind map and just figure out what you want personally, what you want within your career and then figure out what overlaps and where you want to head. And it was really just in the past few days that I've been really thinking about my strength in the field and my strengths within MURRA and the changes that I could make in communities long term.

Making strong, deep relationship fast through the cohort model and intensive education mode of delivery facilitated MURRA participants in pushing through some internal barriers. Acting as sounding boards, and peer coaches to each other through that connection has been influential in connecting personal development with the business skills they are learning in the program. The parallel process of the work participants do through the relational connections with other participants and the business education content creates an atmosphere of strong commitment to work through issues of motivation, dealing with fear about change or getting ready to take that leap into the next big opportunity.

\section{Principle 4: Collective Motivation}

Indigenous learners enter higher education with individual and collective motivations incorporating cultural, educational and business objectives. 
Participants come to the MURRA program with a number of motivations including to learn about business acumen, connect with other Indigenous entrepreneurs and to support Indigenous community initiatives (Evans and Williamson, 2017a). Individual entrepreneurs come to the program with a range of motivations to learn assisting them to effectively address live business issues. Knowles (1980) identifies that learners in the andragogical sense have compelling internal motivations, for MURRA participants that self-motivation is amplified by their Indigenous cultural and community responsibilities.

MURRA is an immense experience. I can't speak highly enough. I've still got all the lecturers notes and so forth and sometimes I just go back over to pick up on something at the time. But it's all the networking and knowing now that there's a whole group of people out there and we've got each other's back and we're all striving in the same direction, to be the best we can be and mostly it's about what we can give back to our own mob, too. (Generation Four participant)

Relational ties built through cohort interaction facilitated individuals to link their selfmotivation to a broader collective motivation within the MURRA program. Being visible and known to other can have many advantages such as creating recommendations and increased business opportunities. Connections built from the MURRA experience assist in bonding and bridging networks allowing Indigenous entrepreneurs to gain advice and tap into larger, more influential business circles. Indigenous businesses can have many advantages such as creating recommendations and increased business opportunities. Providing spaces for the cohort to network within learning activities strongly assisted participants to explore how their self- 
motivations aligned. Networking is an influential process for entrepreneurs to actively build social capital networks and raise their profile. For Indigenous entrepreneurs it facilitates opportunities to work together towards common objectives (Foley and O'Connor, 2013).

.. there are a lot of great Indigenous businesses out there that we can work together with. So, I guess that sense of collaboration that's all been a part of my further development as an entrepreneur.... I think the benefit of mixing with great minds and theories and ideas.... we've done business with some other people in the program and other graduates.... the networking has been fantastic (Generation Two participant).

The capstone masterclass of the MURRA program is Indigenous leadership taught by the only Indigenous faculty member teaching into the program. In the space of this masterclass participants are encouraged to consider how they collectively can accomplish a leadership project in the Indigenous business sector. It is important to note that leadership outcomes were closely linked with both business and Indigenous community initiatives and were recognised by participants as representing individual and collective growth. Leadership was evident in participant responses across political, social and economic contexts, with acts of leadership challenging limitations and encompassing strengths around expertise and values.

...it's given that ability to lead. Before I'd be, and that's where the stress comes, I think for a lot of business owners, in small business, small to medium businesses. It's you feel like you've got to always be there. But when you actually take your hands off and let them fly and then you just have support, it gives that, your life is more enjoyable. (Generation Four participant). 
Belonging to the collective of MURRA is described by participants as a positive experience, with each individual recalling a specific element that makes MURRA distinct for them. Even though participants pronounced different motivations and components of importance, the overall benefits were very similar. The emphasis was on how the teaching and learning related to their business, the collective and to the community more broadly. The benefits were expressed as increased business skills, confidence, being part of a collective environment that encapsulates cultural connections to assist Indigenous business networking, and a validation from participants to endorse the MURRA way of collective leadership in the Indigenous business sector.

\section{Discussion}

Research findings have illustrated that andragogy methods play an integral role in the process of teaching Indigenous business education. This study contributes to the understanding of how andragogy methods can be used successfully in Indigenous business education because they recognise that adult learners are motivated and self-directed which contributes to sustainable learning practices to achieve set goals (Knowles, 1984). Andragogy also acknowledges that an adult is someone who has an assumed societal role in which the learning can inform socially productive actions (Darkenwald and Merriam, 1982). We present in this paper an emergent theory of Indigenous business andragogy. The four andragogy practices we outline are essential in creating conducive learning environments to harness both Indigenous knowledge and business expertise of individuals and the collective group engaged in Indigenous business education. 
Establishing a conducive learning environment is a necessary step in assisting the development of strong relationships between cohort participants. A conducive learning environment allows learners to freely exchange ideas without intimidation or judgement. Cohort models bring together groups of like-minded students and capitalise on their shared knowledge and experience which supports a collaborative learning environment (Imel, 2002; Knowles, 1980). Establishing respectful and mutual learning practices is central to enabling Indigenous learners to safely share their prior knowledge and lived experiences which contributes to the productivity of the learning environment. This environment also allows for participants to set boundaries and expectations of the cohort (Belasen and Rufer, 2007). Producing a safe and inclusive environment encourages students towards feeling a strong sense of belonging. With this concept comes a uniqueness in each cohort's ability to negotiate power and contribution between themselves and with the teaching and program faculty. This environment becomes a site where personal and collective investment in the program are made transparent. This practice is generated from respect and listening to others in relation to personal, cultural and business experiences, thus students appreciate what each individual brings to the collective learning environment (Egri, 1999).

Creating a group identity is imperative in harnessing the collective attributes to work together for a common purpose. An Indigenous cohort model also requires time and space to consider cultural implications, community obligations to reinforce Indigenous ways of knowing and being to make learning more relevant and applicable (Foley, 2006a). With diversity between learners at the forefront of respectful collaborations. Building a purposeful Indigenous cohort needs to take into consideration tension between Indigenous and Western knowledge systems. Collaborative learning spaces provide a protected environment for Indigenous learners to express their point of view and debate cultural contentions. This dialogue space is a major factor in 
forming relationships within a cohort and assists in providing a culturally safe learning environment for Indigenous participants to emphasise their motivations and cultural ways of knowing (Forrest III and Peterson, 2006). Making room in the learning environment for cultural ways of knowing and learning fosters trust and constructs empowerment by respecting the students' abilities to direct their lives and educational endeavours. Mutual and culturally collaborative learning approaches also assist in revealing motivation, as for some individuals Indigenous business education is solely about increasing skills to reinforce economic benefit, while others endeavour to construct a cultural collective to address social and economic disadvantage for the wider Indigenous community (Egri, 1999).

These relational environments become 'think tanks' where Indigenous cultural implications and motivations can be gathered and harnessed into action for specific purposes with actions taking into account the impact of Indigenous business on the broader collective. Through this flexible and culturally progressive learning approach, students adapt and apply knowledge to current business practice which allows problem-solving, reflecting and the application of proven reasoning processes (Knowles, 1980). This relational Indigenous business andragogy acknowledges that collaborative learning practices have great benefit for both the students and the educators, reinforcing that individuals learn from each other as well as gaining discipline specific knowledge through the educators to enhance Indigenous business skills and the Indigenous business environment (Foley, 2006a).

Relational learning is not solely the responsibility of cohort participants alone, there is significant evidence throughout the research that indicates the building of relational ties with educators dually influences the learning of business skills through classroom interactions and collaborative learning opportunities. The use of storytelling is seen as an effective way to build relationships and lead into problem-based learning opportunities constructed for the teaching of 
business skills. Oral storytelling is at the heart of Indigenous cultural traditions and is a powerful tool in educating Indigenous learners (Foley, 2003). Using a storytelling approach is a favourable way for educators to build strong relational bonds with Indigenous learners (Foley, 2003). Through the educator sharing their background and expert knowledge foundations of credibility are established and create a relatable working relationship within the classroom. This approach also reflects and acknowledges that storytelling processes are an important component in Indigenous cultural learning practices (Choy and Woodlock, 2007). The research reflects that collaborative and respectful storied interactions provide highly valued and influential interactions to develop the building of business skills and ongoing mentorship which in turn influences future business practice and position the educator as a facilitator of knowledge and ongoing resource rather than a standard lecturer (Knowles, 1980).

Best practice asks educators to acknowledge that Indigenous learners possess a broad range of cultural and discipline specific knowledge that is a deep and rich resource of wisdom that can be utilised in solving real world problems (Knowles, 1984; Imel, 2002; Hunter and Foley, 2014). Problem-based learning approaches allow for collaborative and integrated learning opportunities and position Indigenous learners as having specific expertise interwoven in practical and historical experience. Providing contemporary and dynamic tertiary Indigenous business education programs that unlock Indigenous business potential is a way of driving selfdetermining practices (Mason and Brown, 2014). This presents the concept that through selfdetermining practices Indigenous people have the capacity to achieve social and economic change (Langton, 2012). Indigenous business education is seen as a vehicle to drive selfdetermination through the development of Indigenous businesses (Foley, 2006a; Stewart and Pepper, 2011; Hunter and Foley, 2014). 
Indigenous entrepreneurs can be upheld as 'experts' in their field, allowing collaborative teaching and learning environments permits these participants to self-authorise themselves in the learning process of others in the cohort. The self-authorisation process is not solely situated in the classroom but reaches further afield to Indigenous community practices, taking into consideration how cultural authorisation is developed and negotiated (Evans and Sinclair, 2016). The research revealed that there was a relationship between individual educational advancement and individuals developing a leadership identity, some happy to be seen as leaders through their entrepreneurial expertise and success (Falk, 2000; Hardy and Tolhurst, 2014; Foley, 2006a; Morrison et al., 2014). Leadership requires more than knowledge and skills; so many Indigenous entrepreneurs point to how they are still looking for skills to enhance their leadership capabilities. Leadership intention in this space, such as the ability to promote business skills for the wider Indigenous community, links to andragogy concepts of how to use what has been learnt for the benefit of providing support to a real problem experienced by a community.

The integration of Indigenous cultural practices and protocols into the business education learning environments provides a foundation for Indigenous learners to contextualise both individual and collective business practices with their cultural philosophies and obligations. A key component of contextualisation of curriculum is the ability for Indigenous learners to contribute to learning of discipline specific content through relating learned content to their Indigenous world. This makes connections between Indigenous business education and how cultural knowledge can be used in real-world contexts.

This research shows that effective business education programs need to provide a space for Indigenous cohort perspectives to be a part of the contextualisation of content. This approach allows Indigenous learners to connect with the content being taught and readily apply this knowledge to their own circumstances. Through this process it is acknowledged that Indigenous 
learners have diverse lived experiences but share a similar historical background. With commonalties influencing their learning, playing an important role in harnessing collective power and creating strong bonding networks that are built on foundations of cultural heritage (Foley and O'Connor, 2013). The abovementioned collaborative work practices enable a deeper understanding of business concepts that will better equip students to deal with more complex and unpredictable problems that they will encounter in a business situation (Ashkanasy, 2006: 82). Indigenous learners benefit from connecting with other Indigenous learners which enables them to share and contextualise challenges and build networks to help them address difficulties. These networks built on relational ties and common cultural bonds to provide opportunities for learners within the network to develop and grow in a supported environment from both a cultural and business perspective (Hitt and Duane, 2002). Subsequently there is a strong relationship and evidence to suggest that through problem-based learning approaches Indigenous learners attain skills that assist in developing Indigenous business and enhancing Indigenous business networks.

Providing a collaborative educational setting that encourages peer-to-peer learning and space for Indigenous learners to contextualise content was regarded throughout the research as valuable in relation to building business skills and establishing strong business connections. Participants considered that the collaborative setting provided a great source for learning as the learning experiences were relevant, practical and components were contextualised to real life business situations (Knowles, 1980). At the cohort level contextual factors included the diversity among individuals' cultural and business attributes with age and gender demographics also playing an important role in contextualisation (Stewart and Pepper, 2011; Foley, 2006a; Egri, 1999; Imel, 2002). For educators teaching in the Indigenous business arena there are implications for considering what contextual components overlap and influence the teaching and learning of 
Indigenous entrepreneurs. This is an important factor to consider when educators are preparing the learning environment and how best to navigate the variables for successful learning outcomes. For example the tensions between profit versus purpose, as some Indigenous entrepreneurs often measure success by monetary gain specific to individual wealth while others measure success in relation to cultural and social responsibility to their Indigenous community (Johns, 2006; Kozlowski and Klein, 2000; Rousseau and Fried, 2001). Educators using the Indigenous business andragogy model can align both social and economic benefits rather than placing these components in opposition to one another, finding innovative teaching ways to mutually reinforce these two concepts.

To assist with such network's educators, need to provide a space for Indigenous entrepreneurs to connect and collaborate with other cohort participants enabling contextualisation of business content and fostering spaces to practice business skills. These learning spaces ultimately become incubators during learning activities for the building of social capital. The contextualisation of business skills and practices into Indigenous business situations clearly outlined in the research that colonial historical practices are still a major factor in developing Indigenous businesses in Australia today.

\section{Conclusion}

Success is a subjective idea. Measuring success for Indigenous business along economic terms such as profitability, numbers of employees, export trading have prima facie value but conceal deeper cultural and community terms of success. The interconnection between preparing a successful Indigenous business education program in Australia and the issues of cultural and social responsibility should be considered and understood by universities and educators (Foley, 
2006a; Stewart and Pepper, 2011). Indigenous business education could be a key element in placing Indigenous business as a major component in driving economic self-determination for Indigenous people in Australia. Due to the limited number of effective Indigenous business education programs and the surge of Indigenous businesses in Australia, there is a need to develop a learning theory such as the one we present in this paper. By focusing on teaching practices, we aim to assist in making Indigenous business education in Australia an achievable and desirable goal for the business academy. Future research initiatives should then aim for universities to pursue collaborations with Indigenous businesses, particularly at the start-up stage. This collaboration could explore how Indigenous business education could benefit in the initial stages of establishing Indigenous business skills and how these skills can influence prosperous Indigenous business development and growth. Future explorations can also encompass other aspects, including longitudinal studies exploring the long-term economic benefits of Indigenous business education on the wider Australian economy, these reference points furthermore assisting the tertiary education environment to determine best practice education models and programs.

In examining the andragogy methods in the MURRA Indigenous Business Master Class Program we establish four andragogy principles that can be implemented in the development of Indigenous business education. The andragogy principles acknowledge the embodied and experiential cultural knowledges that individuals bring into the learning environment as well as the cultural ways of learning that Indigenous individuals and groups use to contextualise business content. Further, the andragogy principles place collaborative learning and applied learning approaches are critical to Indigenous learners. Finally, the andragogy principles highlight how both individual and collective motivations that are firm level but also community level are central to providing a stimulus for growth towards self-determination in practice. 
Effective Indigenous business education will increase Indigenous participation in the business sector. The question that remains beyond this research is, what is the future role of Indigenous business education in maximising successful and sustainable Indigenous businesses in Australia? As argued, producing effective andragogy models that include culturally relevant teaching of Indigenous business education is imperative to increase Indigenous enrolments and influence student engagement in the tertiary business education sector. Indigenous business education must provide Indigenous entrepreneurs with effective education that integrates their cultural identity, highlights Indigenous knowledges and allows for the development of skills to support self-determination practices. While economic change for Indigenous people in Australia remains an important goal, the quality of Indigenous business education becomes a strategy for addressing the wider issue of social and economic disadvantage. Significantly, Indigenous business education can provide skills for sustainable business practices and processes for marginalised communities to guide their own economic future.

\section{References}

Altman JC (2000) The economic status of Indigenous Australians. Canberra: Australian National University.

Anderson L (2006) Analytic Autoethnography. Journal of Contemporary Ethnography 35(4): 373-395.

Archibald J-a (2008) Indigenous storywork: Educating the heart, mind, body, and spirit. UBC press.

Ashkanasy NM (2006) Introduction: On the need for a more mature approach to management education. Academy of Management Briarcliff Manor, NY 10510.

Behrendt L, KLarkin S, Griew R, et al. (2012) Review of Higher Education Access and Outcomes for Aboriginal and Torres Strait Islander People: Final Report. Reportno. Report Number|, Date. Place Published|: Institution|.

Belasen AT and Rufer R (2007) Building a competency-based mba from the ground up: Curriculum design and program delivery. Academy of Management Proceedings. Academy of Management Briarcliff Manor, NY 10510, 1-6.

Bodkin-Andrews G, Whittaker A, Harrison N, et al. (2017) Exposing the patterns of statistical blindness: Centring Indigenous standpoints on student identity, motivation, and future aspirations. Australian Journal of Education 61(3): 225-249.

Boje DM (2008) Storytelling organizations. London: SAGE. 
Cajete GA (2016) Indigenous education and the development of indigenous community leaders. Leadership 12(3): 364-376.

Carroll B and Levy L (2010) Leadership development as identity construction. Management Communication Quarterly 24(2): 211-231.

Choy S and Woodlock J (2007) Implementing indigenous standpoint theory: Challenges for a TAFE trainer. International Journal of Training Research 5(1): 39-54.

Cummings S and Bridgman T (2016) The Limits and Possibilities of History: How a Wider, Deeper, and More Engaged Understanding of Business History Can Foster Innovative Thinking. Academy of Management Learning \& Education 15(2): 250-267.

Dar S, Liu H, Martinez Dy A, et al. (2020) The business school is racist: Act up! Organization First Online: 1-12.

Darkenwald GG and Merriam SB (1982) Adult education: Foundations of practice. Ty Crowell Co.

Dewey J (1933) How We Think: A Restatement of the Relation of Reflective Thinking to the Educative Process Vol. 8.

Dewey J (1940) Freedom and Culture. London: Allen \& Unwin.

Dewey J (1996) The collected works of John Dewey. Charlottesville, VA: Intelex Corp.

Dunbar T and Scrimgeour M (2006) Ethics in Indigenous research-connecting with community. Journal of Bioethical Inquiry 3(3): 179-185.

Egri CP (1999) The environmental round table role-play exercise: The dynamics of multistakeholder decision-making processes. Journal of Management Education 23(1): 95-112.

Ellis CS and Bochner AP (2016) Analyzing Analytic Autoethnography. Journal of Contemporary Ethnography 35(4): 429-449.

Evans M and Sinclair A (2016) Containing, contesting, creating spaces: leadership and cultural identity work among Australian Indigenous arts leaders. Leadership 12(3): 270-292.

Evans MM and Williamson IO (2017a) Understanding the central tension of Indigenous entrepreneurship: Purpose, profit and leadership. Academy of Management Proceedings. Academy of Management Briarcliff Manor, NY 10510, 14904.

Evans MM and Williamson IO (2017b) Understanding the Central Tension of Indigenous Entrepreneurship: Purpose, Profit and Leadership. Academy of Management Proceedings 2017(1).

Evans MM and Williamson IO (2017c) Understanding the central tension of Indigenous entrepreneurship: Purpose, profit and leadership. Journal of Australian Indigenous Issues 20(1): 6-22.

Falk I (2000) Human capital and social capital: What's the difference. Adult Learning Commentary 28(8).

Foley D (2003) Indigenous epistemology and Indigenous standpoint theory. Social Alternatives 22(1): 44.

Foley D (2006a) Does business success make you any less Indigenous? Swinburne University of Technology.

Foley D (2006b) Indigenous Standpoint Theory. International Journal of the Humanities 3(8).

Foley D and O'Connor AJ (2013) Social Capital and the Networking Practices of Indigenous Entrepreneurs. Journal of Small Business Management 51(2): 276-296.

Forrest III SP and Peterson TO (2006) It's called andragogy. Academy of management learning \& education 5(1): 113-122. 
Gainsford A and Evans M (2017) Indigenising Curriculum in Business Education. Journal of Australian Indigenous Issues 20: (1) 57-70.

Gainsford AR (2018) Connection to Country - Place-based learning initatives embedded in the Charles Sturt University Batchelor of Law. Legal Education Review 28(2): 1-14.

Gallagher B and Selman M (2015) Warrior Entrepreneur. American Indian Quarterly 39(1): 73 94.

Garsombke DJ and Garsombke TW (2000) Non-traditional vs. Traditional entreprneurs: Emergence of a Native American comparative profile of characteristics and barriers. Academy of Entrepreneurship Journal 6(1): 93-100.

Gaudry A and Lorenz D (2018) Indigenization as inclusion, reconciliation, and decolonization: navigating the different visions for indigenizing the Canadian Academy. AlterNative: An International Journal of Indigenous Peoples 14: 218-277.

Gladstone J (2018) All My Relations: An Inquiry into a Spirit of a Native American Philosophy of Business. American Indian Quarterly 42(2): 191-214.

Hardy C and Tolhurst D (2014) Epistemological Beliefs and Cultural Diversity Matters in Management Education and Learning: A Critical Review and Future Directions. Academy of Management Learning \& Education 13(2): 265-289.

Hitt MA and Duane R (2002) The essence of strategic leadership: Managing human and social capital. Journal of Leadership \& Organizational Studies 9(1): 3-14.

Hjorth D (2003) In the tribe of Sisyphus: rethinking management education from an “entrepreneurial” perspective. Journal of Management Education 27(6): 637-653.

Hudson S (2016) Awakening the 'Sleeping giant': The hidden potential of Indigenous business. Policy 32(1): 3-9.

Hunter B and Foley D (2014) Indigenous entrepreneurship: Establishing some definitions and theoretical perspectives. International Council for Small Business.

Hunter BH, Radoll P, Schwab J, et al. (2015) Business-related studies and Indigenous Australian students. Centre for Aboriginal Economic Policy Research, ANU.

Imel S (2002) Adult Learning in Cohort Groups. Practice Application Brief No. 24.

Johns G (2006) The essential impact of context on organizational behavior. Academy of management review 31(2): 386-408.

Knowles MS (1980) The modern practice of adult education (revised and updated). New York: Cambridge.

Knowles MS (1984) Andragogy in action. Jossey-Bass San Francisco.

Kolb AY and Kolb DA (2009) Experiential learning theory: A dynamic, holistic approach to management learning, education and development. The SAGE handbook of management learning, education and development. 42-68.

Kozlowski SW and Klein KJ (2000) A multilevel approach to theory and research in organizations: Contextual, temporal, and emergent processes.

Kwaymullina A (2016) Research, ethics and Indigenous peoples. AlterNative: An International Journal of Indigenous Peoples 12(4): 437-449.

Kwaymullina A (2019) Teaching for the 21st century: Indigenising the law curriculum at UWA. Legal Education Review 29(1): 1-30.

Langton M (2012) The Quiet Revolution: Indigenous People and the Resources Boom. 2012 Boyer Lectures. Australia: ABC Radio National, 150 minutes.

Lund Dean K and Jolly JP (2012) Student Identity, Disengagement, and Learning. Academy of Management Learning \& Education 11(2): 228-243. 
Maritz A and Foley D (2018) Expanding Australian Indigenous Entrepreneurship Education Ecosystems. Administrative Sciences 8(2): 20.

Mason C and Brown R (2014) Entrepreneurial ecosystems and growth oriented entrepreneurship. Final Report to OECD, Paris 30(1): 77-102.

Minefee I, Rabelo V, Stewart O, et al. (2017) Repairing Leaks in the Pipeline: A Social Closure Perspective on Underrepresented Racial/Ethnic Minority Recruitment and Retention in Business Schools. Academy of Management Learning \& Education 17(1): 79-95.

Moreton-Robinson A (2013) Towards an Australian Indigenous Women's Standpoint Theory. Australian Feminist Studies 28(78): 331-347.

Morrison M, Collins J, Basu P, et al. (2014) Determining the factors influencing the success of private and community-owned indigenous businesses across remote, regional and urban Australia.

O'Hara M (2003) Cultivating consciousness: Carl R. Rogers's person-centered group process as transformative androgogy. Journal of Transformative Education 1(1): 64-79.

Peredo AM (2005) Community venture in Agua Dulce: The evolution of civic into economic democracy. The Journal of Applied Behavioral Science 41(4): 458-481.

Rousseau DM and Fried Y (2001) Location, location, location: Contextualizing organizational research. Journal of Organizational Behavior: The International Journal of Industrial, Occupational and Organizational Psychology and Behavior 22(1): 1-13.

Schaper M (1999) Australia's Aboriginal Small Business Owners: Challenges for the Future. Journal of Small Business Management 37(3): 88-93.

Schwabenland C (2010) Surprise and Awe: Learning From Indigenous Managers and Implications for Management Education. Journal of Management Education 35(1): 138153.

Shirodkar S, Hunter B and Foley D (2018) Ongoing growth in the number of Indigenous Australians in business.

Sinclair A (2007b) Teaching leadership critically to MBA's: Experiences from heaven and hell. Management and Learning 38(4): 461-475.

Somerville C, Somerville K and Wyld F (2010) Martu storytellers: Aboriginal narratives within the academy. The Australian Journal of Indigenous Education 39(S1): 96-102.

Stewart D and Pepper MB (2011) Close Encounters: Lessons From an Indigenous MBA Program. Journal of Management Education 35(1): 66-83.

Swain J and Hammond C (2011) The motivations and outcomes of studying for part-time mature students in higher education. International Journal of Lifelong Education 30(5): 591-612.

Verbos AK, Gladstone JS and Kennedy DM (2011) Native American values and management education: Envisioning an inclusive virtuous circle. Journal of Management Education 35(1): 10-26.

Vince R (2011) The spatial psychodynamics of management learning. Management Learning 42(3): 333-347.

Vygotsky LS (1978) Mind in society: The development of higher mental process. Cambridge, MA: Harvard University Press.

White JM (2011) Histories of Indigenous-settler relations: Reflections on internal colonialism and the hybrid economy. Australian Aboriginal Studies 1: 81-96.

Yunkaporta T and Shillingsworth D (2020) Relationally responsive Standpoint. Journal of Indigenous Research 8(2020): 16. 


\section{University Library}

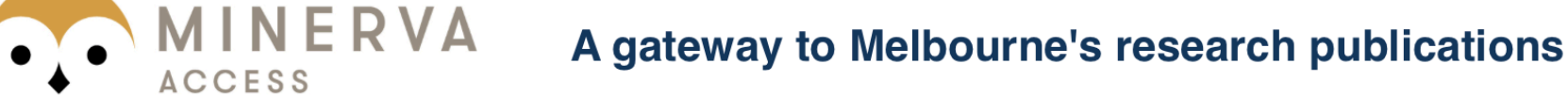

Minerva Access is the Institutional Repository of The University of Melbourne

Author/s:

Gainsford, A;Evans, M

Title:

Integrating andragogical philosophy with Indigenous teaching and learning

Date:

2020-12-02

Citation:

Gainsford, A. \& Evans, M. (2020). Integrating andragogical philosophy with Indigenous teaching and learning. MANAGEMENT LEARNING, 52 (5), pp.559-580. https:// doi.org/10.1177/1350507620972528.

Persistent Link:

http://hdl.handle.net/11343/258873 